\title{
A representação dos Povos Indígenas em livros didáticos de Língua Portuguesa
}

\author{
Representation of indigenous peoples in Portuguese Language Textbooks
}

\author{
Rejane Cristine Santana Cunha* \\ Universidade Estadual de Feira de Santana \\ Feira de Santana, Bahia, Brasil \\ Irlena Moreira Lopes de Sousa** \\ Universidade Estadual de Feira de Santana \\ Eunápolis, Bahia, Brasil \\ Valdete Venturote Bastos*** \\ Universidade Estadual de Feira de Santana \\ Eunápolis, Bahia, Brasil
}

\begin{abstract}
Resumo: O presente artigo tem por objetivo verificar, em dois materiais didáticos de língua portuguesa do $9^{\circ}$ ano do Ensino Fundamental, a abordagem realizada acerca do ensino de história, línguas e culturas indígenas em sala de aula; e discutir posturas pedagógicas de valorização à diversidade étnica. Como embasamento teórico, nos apoiamos em Stuart Hall (2011) e Tomaz Tadeu (2011), para um suporte concernente às discussões sobre cultura e identidade; Moita Lopes (2003) e Rajagopalan (2003), linguistas aplicados que abordam o ensino de línguas em uma perspectiva político-cultural; os Parâmetros Curriculares Nacionais - PCN (1998), que propõem a inserção da temática etnicorracial no contexto escolar. Exploramos uma metodologia que parte da análise comparativa dos livros Diálogo: Língua Portuguesa, do $9^{\circ}$ ano, lançado pela Editora FTD (2009) e o livro do Projeto Araribá: Língua Portuguesa, do $9^{\circ}$ ano, publicado pela Editora Moderna (2010). Com as análises realizadas nas questões propostas pelos livros didáticos, detectamos caminhos que possibilitam reflexão e compreensão acerca da identidade e das diferenças entre as culturas indígenas, o contexto histórico de suas línguas, bem como o legado linguístico-cultural na formação do povo brasileiro, o que é relevante para a discussão no contexto escolar.
\end{abstract}

Palavras-chave: Materiais didáticos. Identidade. Povos Indígenas.

\begin{abstract}
The present article aims to verify in two Portuguese - language didactic materials of the 9th grade of Elementary School, the approach taken on the teaching of history, indigenous languages and cultures in the classroom; and discuss pedagogical positions of appreciation for ethnic diversity. As a theoretical basis, we rely on Stuart Hall (2011) and Tomaz Tadeu (2011) for support concerning discussions on culture and identity; Moita Lopes (2003), Rajagopalan (2003) that brings us an approach on applied linguistics for language teaching from a political-cultural perspective; The National Curricular Parameters - PCN (1998) that evidences the insertion of the ethno-racial theme in the school context. We explore a methodology based on the comparative analysis of the books Dialogue: Portuguese Language, 9th grade, published by Editora FTD (2009) and the book Araribá: Portuguese Language, 9th grade, published by Editora Moderna (2010). With the analyzes carried out in the questions proposed by the textbooks, we detected ways that allow reflection and understanding about
\end{abstract}

* Mestre em História Regionai e Loca' professora assistente da Universidade Estadual de Feira de Santana. Email: resantana110@r.utmail.com.

** Mestre em Educação e Contemporaneidade, professora assistentes da Universidade do Estado da Bahia. Email: imlsousa@yahoo.com.br.

*** Mestre em Educação e Contemporaneidade, professora assistentes da Universidade do Estado da Bahia. Email: ventubastos@yahoo.com.br. 
the identity and difference of indigenous cultures, the historical context of their languages, as well as the linguistic-cultural legacy in the formation of the Brazilian people, which is relevant to the discussion in the school context.

Keywords: Didactic materials. Identity. Indian people.

\section{INTRODUÇÃO}

No contexto contemporâneo, estudos sobre os povos indígenas estão em evidência, principalmente em termos culturais e históricos. Esse protagonismo indígena foi evidenciado a partir da elaboração da lei 11.645, de 10 de março de 2008, que propõe a inserção da temática na proposta curricular de ensino e a sua conseqüente inclusão na produção dos Livros Didáticos de Língua Portuguesa - LDLP. Vale ressaltar que a inclusão da temática na lei é resultado do trabalho de diversos setores, principalmente, dos povos indígenas. É, em suma, uma conquista de muitos anos.

Nessa perspectiva, o Ensino de Línguas e Culturas Africanas, Afro-brasileiras e Indígenas, é sem dúvida um assunto de interesse nos meios de comunicação, como também na academia. Notadamente, essa lei se complementa à lei maior, Lei 9394/1996 das Diretrizes e Bases da Educação -LDB (1996), a qual determina as diretrizes e as bases da organização do sistema educacional no Brasil.

Dessa forma, poderemos perceber as mudanças e permanências em relação às representações dos indígenas em livros didáticos e verificar como está sendo tratada a questão atualmente. Tal cenário nos reporta a fazer os seguintes questionamentos: os livros didáticos de Língua Portuguesa do Ensino Fundamental II trazem alguma abordagem sobre os povos indígenas? Se isto acontece, de que forma estes povos são representados? A intervenção pedagógica desses livros didáticos está de acordo com as recomendações do MEC (Ministério da Educação e Cultura), considerando a aplicação da Lei 11.645/08? Para atender a essas inquietações, utilizamos a metodologia comparativa entre o livro da coleção Diálogo: Língua Portuguesa do $9^{\circ}$ ano, da Editora FTD (2009); e o livro do Projeto Araribá: Língua Portuguesa, do $9^{\circ}$ ano, da Editora Moderna (2010), a fim de analisar, nos referidos livros, se existe uma preocupação com o ensino da história, língua e cultura indígenas em sala de aula, bem como discutir posturas pedagógicas de valorização à diversidade étnica.

Interessa-nos destacar que na LDB estão previstos o direito à educação, o dever de educar, as finalidades e os princípios da educação nacional, além de sua organização em modalidades de ensino, dentre outras abordagens referentes ao sistema educacional e que, a partir disto, com efeito, faz-se também necessário discutir a formação de educadores com base nessa nova configuração referente ao ensino da História, Cultura e Língua dos povos indígenas, e tratar de algumas mudanças relacionadas à questão étnica nos livros didáticos, observando se estão sendo implementadas as propostas da Lei 11645/08, e de que forma é elaborado esse material. Nessa mesma direção, intenta-se vislumbrar uma maneira de compreender a reconstrução de mitos e a formação da 
identidade indígena no campo educacional, em particular para as Letras; é imprescindível avaliar como as noções de identidade estão sendo erigidas a fim de diferenciar o objetivo de determinados manuais didáticos editados.

\section{POVOS INDÍGENAS DO BRASIL}

A representação dos povos indígenas no cenário brasileiro acontece de forma inventada e baseada no legado histórico versado pelo branco colonizador, pois a saga dos povos indígenas começou a ser narrada pelos cânones da história do Brasil e historicizada com a presença do colonizador, a partir de 1500. Esse legado histórico, conforme Cunha (2010, p. 25), foi crucial para a caracterização homogênea destes povos, sem um entendimento das diferenças significativas referentes à etnia, à cultura e à história. A pluralidade étnico-cultural nunca fora percebida por colonos e jesuítas, o que contribuiu para uma representação simbólica de um coletivo de indivíduos, denominados de índios, e que para o colonizador e jesuítas seriam tratados por gentios da terra.

A Companhia de Jesus, na pessoa do Pe. José de Anchieta, apresenta uma referência de indígenas mesclados entre selvagens e inaptos ao convívio social. De acordo com Anchieta, "[...] são de forma bárbaros e indômitos, que parece aproximar-se mais à natureza das feras que as dos homens" (ANCHIETA,1933, p.46). Essa representação de índio perpassou o imaginário da sociedade brasileira, cristalizando imagens dos indígenas como de seres incapazes, pertencentes a culturas inferiores e que, portanto, necessitariam de uma intervenção tutelar, a qual serviria para orientá-los e direcioná-los conforme interesses políticos. Assim, surge uma Política Indigenista no Brasil voltada para uma "proteção aprisionada" e padronizada aos costumes de cada época.

Contrariando essa imagem oficializada no percurso histórico, nota-se a presença de povos indígenas resistentes à proposta de dominação colonizadora, como afirma Beatriz Perrone-Moisés: "As causas legítimas de guerra justa seriam a recusa à conversão ou o impedimento da propagação da Fé, a prática de hostilidades contra Vassalos e aliados dos portugueses (especialmente a Violência contra pregadores, ligada à primeira causa) e a quebra de pactos celebrados". (MOISÉS-PERRONE, 1992, p.123)

A referência de selvagens e hostis era atribuída às etnias que se negavam ao cativeiro tutelar, o que justificava a necessidade da guerra justa. Rotulá-los como indolentes e arredios foi uma estratégia do colonizador para negar o perfil guerreiro desses índios. Assim, fontes registradas por cronistas da época dão-nos indícios de que mesmo com a ação missionária dos jesuítas na costa brasileira, numa perspectiva eurocêntrica, havia resistência por parte dos nativos da terra:

[...] mais de um jesuíta esteve encarregado de aprender a língua da terra para colaborar no aprendizado com os demais e produzir doutrinas da língua indígena, para melhor fruto da catequese/ É compreensível que sendo os portugueses uma ínfima minoria no litoral, não houvesse meios de obrigar os habitantes da terra a adotar a língua portuguesa. Ao contrário, senhores do litoral (e, em geral, guerreiros valorosos, como os Tupinambás), é justificável 
que essa maioria indígena impusesse ao estrangeiro a adoção da língua local como recurso para a comunicação. (D’ANGELIS, 2007, p. 6-7).

Parodiando o escritor Oswald de Andrade, partindo do poema Erro de Português(1925), nesse período "O índio foi quem vestiu o português", impondo ao estrangeiro a sua a língua e valores culturais, visto que, para tentar dominá-los era necessário que o colonizador conhecesse a língua daquele. Com essas ações e o fim da missão inaciana, o poder de tutela aos índios foi delegado aos Diretórios Indígenas (Séc. XVIII), sob o comando do Marquês de Pombal (1754) que proibiu o uso da língua geral ${ }^{1}$, bem como costumes, crenças e tradições indígenas. Assim, por decreto Lei, acontece o movimento denominado como "deculturação" quando se retira de uma comunidade nativa o direito à prática de sua língua e tradições culturais (VAINFAS, 1989, p. 16). Os diretórios enfrentaram diversos problemas pelos abusos de poder dos seus dirigentes por desvio das normas que estabeleciam o período de um semestre pela prestação de serviços dos índios nas vilas; o mesmo se justifica por excessivas jornadas de trabalho, provocando mortes e fugas, o que contribuía para o fracasso da experiência. A política pombalina buscava incorporar o índio à sociedade dos brancos, transformando-o em um trabalhador ativo, voltado à produção agrícola, a fim de assegurar o povoamento e a defesa do território colonial, em uma visão uniformizada e em total desrespeito à diversidade cultural desses povos.

O Serviço de Proteção ao Índio - SPI (1910), liderado pelo Marechal Cândido Rondon, influenciou seguidores ao processo de conquista de índios refugiados nas matas dos ermos sertões do Brasil e defendeu a bandeira do Evolucionismo $^{2}$ e Assimilacionismo $^{3}$, considerando que por esse processo aconteceria a integração de grupos indígenas à sociedade nacional. Nesse contexto, adotou-se uma política "[...] de preservar a possibilidade de sobrevida, de proteger o encontro que sempre foi fatal quando travado diretamente entre a sociedade envolvente e os índios" (CUNHA, 1992, p.155).

A Fundação Nacional do Índio - FUNAI (1967) - com poderes de representação e assistência jurídica ao regime tutelar do índio, acreditava em um trabalho de integração progressiva e harmoniosa, dentro de padrões prontos e únicos para atender a uma demanda diferenciada. Vale salientar que este processo ocorreu durante a ditadura militar, cujo intuito era o investimento em projetos de desenvolvimento do país. Como os índios,

\footnotetext{
${ }^{1}$ Língua indígena também conhecida como Tupinambá que serviu nos séculos XVI e XVII para catequização indígena, tornou-se a língua mais usada na costa brasileira, recebendo dos portugueses o nome de língua brasílica, $e$ se firmou como o idioma dos casais de Lingua geral Paulista e Lingua Geral Amazônica eram línguas mestiçadas que foram perdendo recursos gramaticais e sintáticos da língua indígena original. Ver: NOLL, Volker; DIETRICH, Wolf. O papel do tupi na formação do português brasileiro. In: O português e o tupi no Brasil. 1ed. São Paulo: Contexto, 2010.

${ }^{2}$ Evolucionismo (antrpol soc) refere-se à doutrina segundo a qual toda a cultura de uma sociedade é resultado constante de um processo evolutivo. Ver LACERDA, Rosane Freire. Diferença não é incapacidade: gênese e trajetória histórica da concepção da incapacidade indígena e sua insustentabilidade nos marcos do protagonismo dos povos indígenas e do texto constitucional de 1988. 2007. 2 v. Dissertação (Mestrado em Direito) -Universidade de Brasília, Brasília, 2007.

3 Assimilacionismo está relacionada à corrente que preconiza a assimilação de culturas periféricas pelas culturas dominantes. Ver LACERDA, Rosane Freire. Diferença não é incapacidade: gênese e trajetória histórica da concepção da incapacidade indígena e sua insustentabilidade nos marcos do protagonismo dos povos indígenas e do texto constitucional de 1988. 2007. 2 v. Dissertação (Mestrado em Direimto) -Universidade de Brasília, Brasília, 2007.
} 
contudo, posicionavam-se como "obstáculos" para tais realizações, o papel da FUNAI seria de pacificá-los e integrá-los à sociedade dominante, em favor do desenvolvimento econômico, para que as vastas áreas territoriais ocupadas por comunidades indígenas se tornassem posses de latifundiários.

Assim, foi pelo enfrentamento que as lideranças indígenas chegaram ao Congresso Nacional e participaram da Constituição dos Direitos Indígenas (1988), cujo regimento traria o reconhecimento da variedade sociocultural da sociedade brasileira e os direitos das populações indígenas de viverem e preservarem seus próprios sistemas socioeconômicos e culturais. Com essa ação, aboliu-se a ideia assimilacionista e criou-se o novo Estatuto do Índio, buscando o direito de autodeterminação das populações indígenas e o controle sobre seus territórios, ratificado pelo Congresso Nacional através da convenção 169 da Organização Nacional do Trabalho - OIT 64. Consoante Roseane Lacerda

[...] como representantes desse povo, estão Ailton Krenak, Enayê Mairê Guarani, Nelson Saracura Pataxó, Gilberto Macuxi, Manoel Moura Tucano, dentre outros que fizeram a diferença na sociedade nacional, cujos discursos constam nas atas de Comissão da Assembléia Nacional como participantes na elaboração da constituição cidadã, no Congresso Nacional, 1987/1988, fato inédito na história do país e do constitucionalismo brasileiro (LACERDA, 2008, p. 72).

A partir de então, deixa-se de lado a observação do índio enquanto ser exótico, retratado como retrógrado, primitivo e propõe-se um novo olhar, outra forma de melhorias para a sobrevivência, sem atropelamentos à sua identidade e à afirmação cultural: a população ameríndia cresceu no decorrer da segunda metade do séc. XX, e junto com ela o desejo de autoafirmação frente à comunidade brasileira. Como afirmou Darcy Ribeiro é “[...] o sentimento de identificação tribal que leva estes minúsculos grupos étnicos a lutar por todos os meios para conservar sua identidade e autonomia" (RIBEIRO, 1970, p. 122).

A vivência sociocultural estreitamente vinculada ao território indígena volta ao centro das atenções. A luta pelo respeito às diferenças foi gradativamente ganhando corpo, com manifestos sociais e um crescente número de adeptos reivindicando uma democracia que, de fato, atendesse às demandas de uma sociedade plural (CUNHA, 2010, p.41). Nesta febre de manifestações, as lideranças indígenas se impõem através do Movimento Indígena e de suas lutas por direitos territoriais; reconhecimento e respeito às suas especificidades étnico-culturais. Assim, eles vêm desconstruindo imagens estereotipadas desde a colonização portuguesa até o período republicano, surpreendendonos por mostrarem que são os melhores advogados de suas próprias causas.

\section{O LIVRO DIDÁTICO DE LÍNGUA PORTUGUESA SOB A ÓTICA DOS PCN}

A história do Livro Didático (LD) no cenário brasileiro se consolidou no período do Estado-Novo 1930, com uma proposta de regulamentação para a produção e a 
distribuição de livros didáticos nas escolas. Época em que se buscou desenvolver no Brasil "uma política educacional consciente, progressista, com pretensões democráticas e aspirando a um embasamento científico" (FREITAG, 1987, p. 11).

Com a finalidade de regulamentar uma política nacional do livro didático, esse mesmo decreto criou a Comissão Nacional do Livro Didático (CNLD), formando a primeira comitiva governamental nessa área de política educacional, para que pudesse examinar, avaliar e julgar os livros didáticos, autorizando ou não o uso destes nas escolas.

Criado em um momento político autoritário, bastante acentuado e polêmico, que buscava garantir, sobretudo, a Unidade/Identidade Nacional, a CNLD tinha como tarefa o controle de adoção dos livros, garantindo que eles acatassem aos propósitos de concepção de certo "espírito de nacionalidade", o que colaborou para que os critérios concernentes aos aspectos político-ideológicos superassem as abordagens pedagógicas.

Vale ressaltar que o controle do Estado à atuação da esfera ideológica e econômica no Brasil resultava na própria contratação de seus autores, impressão de livros e distribuição gratuita pelas escolas oficiais. Tal confecção técnica era assegurada por editoras particulares das quais o Estado comprava o produto pronto, depois de passar pelo crivo das comissões de avaliação. (FREITAG, 1987, p. 12).

Na prática docente, o Livro Didático de Português - LDP - em sala de aula representa uma importante referência no processo de ensino/aprendizagem. Composto por conteúdos e atividades preparados para serem seguidos por professores e alunos, acaba, todavia, assumindo "[...] uma importância tal, que o interlocutor dos alunos não é mais o professor, e sim o autor do LDP: interlocutor distante, dificultando a interação com os alunos, e porta-voz presente (professor), quase sem autonomia, seguindo página a página a proposta do autor” (BEZERRA, 2003, p. 14).

Assim, esse absoluto poder do LDP em transitar os saberes monopolizados contribui para uma prática de aprendizagem em perspectiva colonizadora, cujo ideal homogeneizador de ensino de língua ainda comporta a tendência de ignorar as culturas nativas em sua diversidade, ofuscando a importância da contribuição da língua indígena para a formação do Português Brasileiro. Tal poder representa a tentativa de se controlar social e linguisticamente a educação de massa o que, nessa ação pelo próprio estudo da linguagem, promove a desigualdade social. Enfatizamos as reflexões de Pedro Funari, ao afirmar que “[...] não é o caso de negar a relevância da Europa para o nosso continente. Mas isso não pode nos cegar em relação às outras partes essenciais da nossa formação cultural, histórica e antropológica, como é o caso da presença dos indígenas" (FUNARI, 2011, p. 16).

Nesse aspecto, a intenção do ensino de língua portuguesa, segundo os PCN de LP, deixa de ser exclusivamente ao desenvolvimento de habilidades de leitura e de produção ou para o domínio da língua escrita padrão, preocupando-se com o domínio da competência linguístico-textual, indo além dos limites escolares, na solução dos problemas da vida, como no acesso aos bens culturais e à participação plena no mundo letrado, ou seja, cumprindo, de fato, o seu papel de formadora de sujeitos críticos reflexivos e cientes de sua responsabilidade como cidadão. Trata-se de pensar o ensino a partir de uma 
perspectiva que concebe a língua como algo vivo, fundamental nas mais diversas práticas e contextos das experiências humanas, apresentando-se como dinâmica, heterogênea, que comporta as marcas da diversidade que constitui os povos, e não como um conjunto isolado de normas a serem decoradas, as quais pela forma como são trabalhadas, pouco dizem aos sujeitos:

A importância e o valor dos usos da linguagem são determinados historicamente segundo as demandas sociais de cada momento. Atualmente exigem-se níveis de leitura e de escrita diferentes e muito superiores aos que satisfizeram as demandas sociais até bem pouco tempo atrás - e tudo indica que essa exigência tende a ser crescente. Para a escola, como espaço institucional de acesso ao conhecimento, a necessidade de atender a essa demanda, implica uma revisão substantiva das práticas de ensino que tratam a língua como algo sem vida e os textos como conjunto de regras a serem aprendidas, bem como a constituição de práticas que possibilitem ao aluno aprender linguagem a partir da diversidade de textos que circulam socialmente. (BRASIL, 1998, p. 25).

Os temas transversais, como Educação para as Relações Étnicorraciais, também são ressaltados para o fortalecimento de culturas negadas e silenciadas no contexto escolar, mesmo porque é neste espaço que se tem a oportunidade de acesso a uma gama de informações sobre outras culturas e outros povos.

Pode-se dizer que o ensino de LP passa a ser repensado por razões essenciais ao desenvolvimento de novos modelos no campo da linguagem, que norteiam a discussão a partir de informações a respeito de quem ensina e quem aprende; referente à maneira como se forma e como se instrui, sobre língua e linguagem. Análises na área de educação envolvem um empenho de revisão dos métodos de ensino da língua, de conhecimento prévio que o aluno traz para a escola, como também da realidade sociocultural em que o discente está inserido.

Por outro lado, o campo das ciências da linguagem aponta para a percepção da linguagem como forma de intercâmbio intermediária e essencial das relações sociais, para a percepção das diferenças dialetais, para a necessidade de se ensinar a partir da diversidade textual, para adoção das práticas de leitura, produção e análise linguística em suas condições de uso e de reflexão como conteúdo da disciplina.

Nesse discurso produzido pelos PCN de Língua Portuguesa, pode-se perceber que historicamente o LDP sempre foi visto como um artefato organizador da ação docente e, após a implementação da lei 11.645/2008, o LDP deve trazer uma proposta voltada para um ensino inovador e expressivo.

Pelas Diretrizes Curriculares Nacionais - DCN (2004), para educação das relações etnicorraciais, o ensino deve ter três princípios: consciência política e histórica da diversidade; fortalecimento de identidades e de direitos; ações educativas de combate ao racismo e às discriminações (BRASIL, 2004). Tais princípios se desdobram em diversas ações e posturas a serem tomadas pelos estabelecimentos de ensino.

Os livros didáticos de língua portuguesa devem trazer em si a história vivida por cada indivíduo, o que permite uma apropriação além da leitura, bem como a apreensão 
dos outros conteúdos da língua portuguesa. No entanto, a história dos povos indígenas não aparecia nos livros didáticos, sua cultura e movimentos organizados em busca de direitos na sociedade não constavam nos manuais escolares. Assim, tem-se a invisibilidade destes povos no material de ensino, o que é uma forma de exclusão. E, quando alguns manuais trazem informações sobre o índio, isto acontece de forma estereotipada, apresentando-o como submisso, deslumbrado por objetos trazidos por colonizadores, assumindo um comportamento de sujeito pacífico, aceitando todas as imposições dos portugueses com benevolência. Para evidenciar esta afirmação, cita-se um excelente exemplo que é A carta de Caminha, escrita por Pero Vaz de Caminha, a qual registra as impressões sobre a nova terra e seus habitantes, mostrando o índio como uma tábula rasa, pronto a receber as informações de um povo civilizado e superior. O que se tem, em suma, é a agressão à cultura deste, à sua identidade e memória, por uma terrível negação aos seus direitos e diversidade, o que é bastante visível no silenciamento que marca as páginas dos livros didáticos de Língua Portuguesa.

Sobre este aspecto, as representações do mundo social são determinadas pelos interesses dos grupos que as fabricam. Para o autor, a leitura de um texto impresso pode gerar sentidos, os quais se relacionam com as formas recebidas pelos leitores e ouvintes. Esses sentidos múltiplos são atribuídos aos textos mediante sistema de representação cultural de cada povo. (CHARTIER, 2002, p. 121-139).

Com a aprovação da Lei 11.645/08, que propôs alterar e estabelecer novas Diretrizes e Bases à Educação Nacional (BRASIL, 2004), tornando obrigatória a temática Indígena nas salas de aula de todo o território nacional, houve uma intenção, por lei, de valorização dos aspectos da história e cultura, que caracterizam a formação da população brasileira, enfatizando as contribuições dos povos indígenas, no que se refere às áreas sociais, adentrando, claro, o campo político, econômico e cultural da História do Brasil.

\section{IDENTIDADE E SUAS IMPLICAÇÕES NO PROCESSO DE ENSINO}

Discutir identidade, hoje, no Brasil, tornou-se objeto de interesse por parte de estudiosos de diversas áreas do conhecimento, a saber: Filosofia, Psicologia, Psicanálise, Antropologia, Sociolinguística, Análise do Discurso, Linguística Aplicada, entre outras. O conceito de "identidade" vem sendo debatido nos espaços acadêmicos desde o século XVIII, tendo ressonância significativa na contemporaneidade para práticas educativas humanizadas numa perspectiva multicultural. Na área de linguagens, de forma significativa, a linguística aplicada contribui para esse olhar, uma vez que "[...] a ética da linguística aplicada crítica, seja ela anti-hegemônica, mestiça ou híbrida deve acontecer de forma ética porque, sendo marginal, não tem uma dimensão etnicida. Tampouco se apresenta com propósitos proselitistas, ligados à correção de inverdades e a proclamação da verdade única”. (KLEIMAN, 2013, p. 47). Nessa postura, o ensino de línguas deve oportunizar, em gêneros diversificados, a inserção de grupos sociais minoritários, engendrando uma prática ética, humanista, que concebe o sujeito como um ser 
multifacetado, que se constitui na linguagem e parte desta para o seu agir no mundo consigo e com o outro.

Não se trata de proclamar verdades "absolutas", "únicas", mas de abarcar também os sujeitos que não dispõem de estruturas importantes de poder e que são silenciados, quando não estereotipados e deformados para anular suas possibilidades de reação, conferindo-lhes o direito à representação das memórias diversificadas para democraticamente compor o espaço escolar. A questão a ser realçada, em se tratando do ensino de língua, é ter uma práxis mais humana, capaz de reconhecer o outro em sua alteridade como um sujeito único, que faz parte de uma cultura singular, com suas idiossincrasias, identificando as diferenças entre os povos como uma possível forma de agregar valores às experiências dos sujeitos e não como ferramenta de exclusão, de valorar culturas e sujeitos, atribuindo a uns o lugar de superiores e a outros, o da inferioridade.

$\mathrm{Na}$ verdade, trabalhar com a língua exige uma postura crítica e capaz de compreender o ser humano imerso em culturas, o que dialoga com as reflexões de Stuart Hall, para quem o sujeito na modernidade tardia, sofreu deslocamento, configurando-se como um indivíduo descentrado, não fixo, não essencialista e nem individual. $\mathrm{O}$ autor compreende as identidades pós-modernas como fragmentadas, abertas, contraditórias e inacabadas. A identidade é vislumbrada como algo formado ao longo do tempo, pelo meio de processos inconscientes e não algo congênito, existente na consciência no momento do nascimento. Ela permanece sempre incompleta, está em constante processo de construção. (HALL, 2006, p.74). Considerando esse argumento, a identidade plenamente unificada, completa, segura e coerente é uma fantasia.

Em toda parte, estão emergindo identidades culturais que não são fixas, mas que estão suspensas, em transição, entre diferentes posições; que retiram recursos, ao mesmo tempo, de diferentes tradições culturais; e que são o produto desses complicados cruzamentos e misturas culturais que são cada vez mais comuns no mundo globalizado (HALL, 2006, p. 88).

Dessa forma, as identidades podem ser desestabilizadas e também desestabilizadoras na medida em que estão situadas em diferentes contextos culturais. $\mathrm{O}$ controle social e o imaginário, as expectativas de papeis e a sua realização marcam simbolicamente a prática social.

As culturas hoje se encontram mescladas e, de acordo com Canclini, dialogam entre si e, para muitos estudiosos, têm se tornado homogeneizadas, recebendo assim, uma nova nomenclatura "culturas", não sendo mais possível referir-se a elas como uma coisa uma [...] (CANCLINI, 2011, p. 46). Este fator foi possibilitado pela intensificação do processo de globalização, que proporcionou o encurtamento das distâncias e a propagação, em escala mundial, da narrativa dos meios de comunicação, grandes responsáveis por ligarem pessoas das mais diversas partes do mundo. Mas, o fato é que essa homogeneização é possibilitada, principalmente, pela uniformização do consumo e por consequência, o imperialismo da cultura Norte Americana como modelo de vida. 
A temática das identidades surge nos estudos linguísticos guiada por uma concepção de linguagem como discurso, ou seja,

[...] uma concepção que coloca como central o fato de que todo uso da linguagem envolve ação humana em relação a alguém em um contexto interacional específico, [...] todo ato discursivo se dirige a alguém e toda prática discursiva é situada no mundo sócio-histórico e cultural em que ocorre, isto é, não ocorre em um vácuo social. (MOITA LOPES, 2003, p. 22).

Essa abordagem comunga, necessariamente, com identidade e ideologia, ao passo que é compreendida como representativa e não constitutiva da vida social. Para tanto, de acordo com Fabrício e Moita Lopes, nessa perspectiva, "os indivíduos passam a ser compreendidos como agindo em práticas discursivas específicas que os constituem em certas direções de forma situada e contingente" (MOITA LOPES, 2003, p. 13). Assim, a língua é norteadora também do sujeito social e medida em seus processos de identificação. Essa relação do indivíduo com a língua é tão intensa que não conseguimos definir uma pessoa separadamente da sociedade, ainda que cada um de nós tenha determinadas 'marcas de autenticidade'. Há uma relação indissociável da identidade com a língua e com o contexto.

Para completar esse pensamento, Rajagopalan nos lembra de que "[...] as línguas são híbridas e possuem instabilidades estruturais e constitutivas" (RAJAGOPALAN, 2003, p. 127). A língua e, consequentemente, a linguagem está em constante construção, algo que o sujeito recria e remolda de acordo com o momento histórico (idem, p. 25). Assim, é importante ressaltar que a reconstituição do sujeito, que nunca se encerra, sempre se fará a partir de uma identidade própria e não apesar dela. "A identidade é marcada pela diferença, mas parece que algumas diferenças - neste caso entre grupos étnicos - são vistas como mais importantes que outras, especialmente em lugares particulares e em momentos particulares" (SILVA, 2003, p. 10-11). Os diversos grupos étnicos e a representação de suas culturas são compreendidos de forma diferente, o que significa que está em pauta o elemento social e simbólico, que

[...] referem-se a dois processos diferentes, mas cada um deles é necessário para a construção e a manutenção das identidades. A marcação simbólica é o meio pelo qual damos sentido a práticas e a relações sociais, definindo, por exemplo, quem é excluído e quem é incluído. É por meio da diferenciação social que essas classificações da diferença são "vividas" nas relações sociais (WOODWARD, 2006, p. 14).

Por muito tempo pensou-se que a identidade fosse algo único, biológico e imutável, desconsiderando as particularidades dos sujeitos e suas culturas. E, no caso do indígena, era necessário ser moldado para caber em um projeto de civilização do colonizador.

Nessa perspectiva, ser índio é ser diferente de qualquer outra coisa, algo transcendente [...]. Essa diferença de condição era reconhecida até mesmo em termos legais, pois os índios eram 
insetos, inimputáveis, não eram cidadãos, eram como se fossem menores, irresponsáveis. Mas podiam e deviam de ser tudo isso e se tornar integrados, assimilados a um todo maior: a nacionalidade brasileira. Essas noções partiam de uma concepção de sociedade fundada no tripé homogeneidade, compartilhamento de valores e respeito às regras sociais. (FUNARI, 2011, p. 21).

Então, o enfoque em questão explicita que nos identificamos de acordo com a nossa cultura, raça ou etnia, religião e ideologia, onde manifestamos nossos valores e afirmamos nossas diferenças identitárias, ideológicas e políticas. Tal atitude deve/deveria constar nos livros didáticos, uma vez que a Lei 11.645/2008 garante essa legitimidade, considerando as diferenças socioculturais das comunidades indígenas, a diversidade linguística e étnico-cultural do território brasileiro, sem perder de vista os atributos identitários tão marcadamente presentes pela diferença racial e étnica dos povos indígenas. Assim, faz-se necessário alertar aos órgãos oficiais que não se deve apenas legitimar, mas fiscalizar e concretizar essas ações ora discutidas.

\section{O LIVRO DIDÁTICO E A TEMÁTICA INDÍGENA}

A partir do exposto, analisaremos dois livros didáticos para o Ensino Fundamental, sendo o primeiro o livro da coleção Diálogo: Língua Portuguesa, do $9^{\circ}$ ano, publicado pela Editora FTD (2009); e o outro do Projeto Araribá: Língua Portuguesa, do $9^{\circ}$ ano, lançado pela Editora Moderna (2010). O objetivo é identificar se houve uma intervenção pedagógica de acordo com as recomendações do MEC (Ministério da Educação e Cultura). A análise considerará a aplicação ou não da Lei 11.645/08.

\subsection{ANÁLISE - "COLEÇÃO DIÁLOGO: LÍNGUA PORTUGUESA - 9 ANO”}

Na seção que compreende a gramática, tem-se um texto narrativo, cujo título é: "As leituras indígenas", de autoria do indigenista Orlando Villas Bôas, das páginas 118 a 121. O texto discorre acerca da leitura em diversas nuanças, fazendo associações à comunidade brasileira não indígena e à comunidade indígena, no sentido de descortinar a ideia de leitura nas diferentes culturas. O texto traz um aspecto positivo, pois ressalta a cultura indígena e cria a possibilidade de desconstrução de conceitos que são lugarescomuns, cristalizados e naturalizados por uma significativa parte da sociedade brasileira, dentro de uma visão estática fora do contexto indígena.

O texto ainda explora outros códigos de leitura, como a leitura espiritual, dos bichos, do tempo, das matas, enfim extrapola o universo da representação gráfica. No que tange à linguagem não verbal correlacionada ao texto em pauta, há algumas mudanças, porque "o índio foi vestido", mas continua ingênuo. Nessa composição de imagens, identificamos esse índio, ainda, preso ao passado da era colonial. Quanto à interpretação textual no que se refere à abordagem, não vislumbra os fatores identitários, tampouco apresenta o índio como sujeito da história, mas como coadjuvante, o que vem corroborar com o pensamento de que "O silenciamento, a invisibilidade histórica, o "encobrimento" 
de diferenças culturais, sociais, étnicas, etárias, de gênero nos currículos escolares serve para legitimar o lugar privilegiado que desfrutam os membros de uma cultura dominante (SANTOMÉ, 1995, p. 159).

É notória a quase completa ausência de aspectos linguísticos, principalmente no conteúdo de estrutura e formação de palavras nas páginas 114 a 115, do referido livro. Para Funari, "[...] mesmo a toponímia, com tantos nomes tupis, atesta a influência do vocabulário nativo na nossa língua oficial. Os indígenas fazem parte da nossa história, da nossa cultura, mas isso nem sempre está claro" (FUNARI, 2011, p. 17). Infelizmente, os materiais didáticos continuam a não reconhecer a contribuição das línguas indígenas na formação do nosso português brasileiro: quando apresentam palavras de origem indígena, chama-se atenção para o seu léxico no campo culinário, geográfico, não evidenciando a mínima abordagem histórica do glotocídio sofrido pelos povos indígenas no período da colonização brasileira, e mesmo proibidos de falarem a sua própria língua, mantiveramna viva, em alguns casos. Mesmo porque em nosso país ainda constam como vivas 180 línguas e que, segundo Rodrigues os povos indígenas “[...] distinguem-se também de nós e entre si por falarem diferentes línguas.[...] embora diferentes, elas compartilham do que todas as quase seis mil línguas do mundo têm em comum: são manifestações da mesma capacidade de comunicar-se pela linguagem" (RODRIGUES, 2002, p. 17).

Na página 124, aparece o texto "O último Quarup" extraído da Revista Raiz, Cultura do Brasil, que faz a última homenagem de despedida à morte de Orlando Villas Bôas, ilustrado com a figura de índios do Xingu, dançando em círculo em forma de ritual, em despedida ao último "cacique branco", como era chamado pelos índios do Xingu. $\mathrm{Na}$ página 130, aparece um quadro sinóptico que apresenta influências de outras línguas no português brasileiro, e uma das línguas presentes foi o tupi com os seguintes exemplos: abacaxi, capim, cipó, carioca. Nada mais foi explicitado, nem mesmo uma reflexão para multilinguismo, heterogeneidade das línguas indígenas, o que foi vivenciado pelos índios que se encontravam em território brasileiro bem antes da chegada de colonizadores europeus, o que também se refere ao termo genérico "índios", designados por seus colonizadores. Em momento algum há um questionamento sobre o porquê alguns povos foram denominados Tupinambás, Tupinquins. Consoante Funari “[...] Tupi significa 'o ancestral', e então ' os descentes do ancestral' são os Tupinanbás ('nambá' quer dizer descente), enquanto 'tupinanki' (o nome original dos tupiniquins) quer dizer o galho do ancestral, em que galho possui sentido de ligações de parentesco" (FUNARI, 2011, p. 18). Diante desta lacuna, torna-se relevante e significativo o trabalho com a análise da língua, na perspectiva da gramática contextualizada.

$\mathrm{Na}$ seção de produção textual, na página 258, o texto apresentado foi "Índio com diploma não é mais índio?”, do autor Jorge Terena, do povo Terena, no Mato Grosso do Sul. $\mathrm{O}$ texto aborda discussões referentes à cultura indígena, à identidade, à educação indígena e à educação escolar indígena, mostrando a diferença entre elas. O texto é contemporâneo e significativo no que diz respeito às discussões sobre a temática indígena. O livro didático trouxe um excelente texto e precisava ser explorado expressivamente, no entanto o enfoque ressaltou, apenas, uma proposta de atividade de interpretação textual 
focada no texto e para o texto. Por outro lado, salienta-se um acréscimo de mais um texto na página 261, em que se discute a educação indígena, fator pertinente, pois chama atenção para o aprofundamento das discussões étnico- culturais e identitárias, como mostra o fragmento extraído do texto em discussão:

[...] Os estudantes indígenas às vezes passam por dificuldade nas cidades, mas por compromisso com suas comunidades insistem em adquirir ferramentas científicas e tecnológicas. Isso os permite discutir de igual para igual com os governos um planejamento de políticas públicas indígenas condizentes com a realidade. Mas por que tanta dificuldade para ajudar um pequeno número de indígenas a concluir os estudos? Índio não precisa estudar?

Diante desse cenário, uma indagação se faz acerca do sujeito social e suas perspectivas: como o sujeito se percebe e como se apresenta diante do outro? De que forma são marcadas as posições de sujeito ante o projeto globalizante, que ora pode massificar ou criar marcadores de resistência? É nessa perspectiva nuclear que a identidade se articula indissociavelmente à diferença. O conceito de identidade é altamente abstrato e ainda volátil por estar em construção as identidades sociais devem ser entendidas " [...] como um feixe de traços identitários que coexistem, às vezes de forma contraditória, na construção das diferenças de que somos feitos" (MOITA LOPES, 2003, p. 28). Neste sentido, para Woodward, a identidade é relacional, construída com e a partir do outro. Por se caracterizar complementarmente no "eu" e no "outro", destaca-se a diferença, que, por sua vez, exerce-se na exclusão. É nesse liame que se delimita uma fronteira tênue entre o que o sujeito é ou pode vir a ser e aquilo que não pode ser através da exclusão do outro de si (WOODWARD, 2011, p.17-18).

\section{2 "PROJETO ARARIBÁ: LÍNGUA PORTUGUESA - 9 ANO”}

Inicialmente, propõe-se desenvolver atividades de produção textual. Na página 76, a partir do texto "Mergulhando na Floresta", de autoria de Airton Ortiz, encontra-se um relato de viagem, que expõe uma travessia de barco pelo rio Ucaiale, na parte peruana da floresta Amazônica. A imagem no interior do texto é de uma embarcação genuinamente indígena: a canoa, além dos dois índios navegando nesta mesma embarcação. O texto, na verdade, apresenta-se como pretexto e exemplificação na orientação das atividades de produção textual, conforme explicita-se o fragmento extraído do texto, o qual é encontrado na página 77.

Analise: observe a organização da descrição

$1^{\circ}$ Observe como é construída a descrição nesse relato.

a) Identifique os elementos selecionados para descrição

b) Indique quais dos cinco sentidos humanos a descrição evoca.

Justifique sua resposta com passagens do texto.

c) Transcreva os termos que expressam movimento. 
d) Transcreva os termos que expressam localização.

Observa-se que nessa atividade não houve, infelizmente, um trabalho de interpretação textual que discutisse acerca da cultura indígena, sobretudo a valorização desta, uma vez que o texto narra e descreve a travessia de dois índios na floresta Amazônica. O equívoco está em não vislumbrar as suas tradições, negando a viabilidade do exercício da prática multicultural, possibilitada pelo encontro de diferentes culturas e, assim, o hibridismo cultural, mediante as migrações entre sujeitos que compartilham outros costumes e crenças. Canclini ressalta que tal processo garantiria a sobrevivência da cultura indígena por trazer consigo a ruptura da ideia de pureza, pois no próprio conceito de multiculturalismo, esses encontros favorecem a diversidade. (CANCLINI, 2011, p. 26).

Na seção que versa sobre "Projeto em equipe", que aparece da página 100 a 103, há uma entrevista com o escritor indígena Daniel Munduruku sobre o seu livro infantil, Kabá Darebu, o qual discute sobre seu povo e seu trabalho. A linguagem não verbal é ilustrada pela imagem do autor indígena vestido com roupas da cultura do não índio. Essa seção traz um aspecto positivo concernente à entrevista com o autor índio formado em filosofia, a qual expõe comentários sobre a cultura indígena, por meio do autor, com o intuito de valorizar a cultura indígena na contemporaneidade:

[...] Locutor 1: No início do mês de junho, o Quarto Encontro de Escritores e ilustradores de Literatura Infantil e Juvenil aconteceu no Rio de Janeiro, dentro do Salão do Livro, no Museu de Arte Moderna.

Locutor 2: Como todo ano, o evento foi organizado pela Fundação Nacional do Livro Infantil e juvenil. A participação dos índios no seminário ocorre, pelo quarto ano consecutivo, no terceiro dia.

A entrevista completa discorre sobre a temática do índio contemporâneo, a ascendência indígena no cenário da Literatura no Brasil, discutindo sobre o povo Munduruku e o seu trabalho, proposta interessante por apresentar o protagonismo indígena e uma oportunidade de desconstruir a imagem de inaptidão dos indígenas perante o domínio da escrita, já que se trata de um Munduruku escritor. Entretanto, essa possibilidade é apresentada de forma tímida, pincelada sem o destaque devido, tanto para a obra literária produzida pelo autor indígena, quanto pela sua própria trajetória de vida. A imagem apresentada pelo autor indígena, com trajes da sociedade envolvente e não caracterizado como o índio de tanga, cocar e indumentárias de sua aldeia revela mais uma possibilidade de se comprovar que os povos indígenas também podem ser cidadãos letrados, que dominam a tecnologia e nem por isso precisam negar a sua identidade, afinal o sentimento de pertença à sua comunidade está em seu próprio testemunho de vida. Este seria um momento oportuno para que o material didático desconstruísse a imagem estereotipada do índio como um ser do passado. Ainda na mesma seção, não se percebe comentários sobre a cultura ameríndia, apenas utiliza-se o texto para desenvolver atividades do gênero oral, no caso, a entrevista. 
A abordagem do livro em questão, nessa atividade, é apenas direcionar atividades que tenham relação com a proposta elucidada no enunciado, que por sua vez compreende a elaboração de texto de reportagem. Assim, a temática indígena não foi pertinente à proposta de inclusão de sua história e seus costumes, conforme a Lei 11645/08. Nesse caso, perde-se uma oportunidade de conhecimento, reflexão, bem como de desconstrução de mitos, o que é uma herança colonial, sobre os nossos antepassados indígenas.

No capítulo intitulado "Questão da língua", na página 221, o texto é um poema de Gonçalves Dias, autor que faz parte da $1^{\text {a }}$ geração do Romantismo brasileiro, denominado "Juca Pirama". Além deste, são mostradas também as figuras de dois índios dançando em meio à floresta. Nesta seção, constatamos a ausência de uma discussão mais aprofundada sobre a temática indígena, ressaltando-se, notoriamente, o texto poético como pretexto para o uso do apóstrofo. O poema Juca Pirama é de uma riqueza imensurável e poderia ser usado por um viés pautado nas discussões da cultura indígena, o que compreenderia o fator linguístico, histórico, cultural, identitário e étnico. No entanto, as atividades sugeridas pelo livro didático exprimem uma visão voltada para o trabalho da gramática pela gramática, sem fazer o uso reflexivo da língua, seus aspectos históricos e o legado lexical (em destaque o tronco linguístico Tupi por ser mais apresentado em seus topônimos, inclusive presentes no próprio poema em destaque):

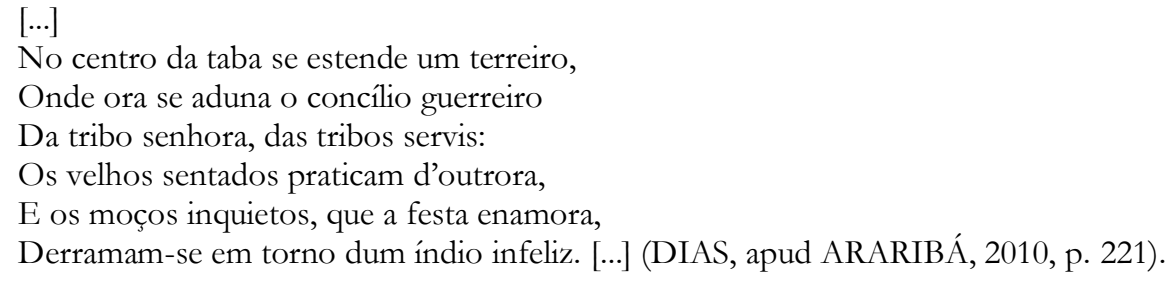

No tocante à linguagem não verbal, a imagem que acompanha o poema é composta por índios guerreando com suas lanças e flechas, o que é recorrente em muitos livros didáticos, ou seja, a apresentação esporádica da figura do índio já inserida no Brasil colônia, como herança do passado, fora de uma abordagem contextualizada e crítica. De acordo com Funari "[...] não devemos esquecer que os índios não foram simplesmente dominados, escravizados, submetidos, aniquilados ou assimilados. Eles constituíram o cerne das culturas americanas coloniais [...]. Não como excluídos, mas como partícipes de um novo amálgama" (FUNARI, 2011, p. 23). Talvez seja a falta de representação positiva, provinda de informações contextualizadas e reflexivas referentes aos povos indígenas, a responsável pelas lacunas no que diz respeito à possibilidade de discussões significativas sobre a temática indígena no livro analisado.

\section{CONSIDERAÇÕES FINAIS}

Após análise dos dois livros didáticos, é importante tecer alguns pontos pertinentes que precisam ser elucidados. O primeiro livro, "Diálogo" demonstrou 
cuidados, ainda que de forma tímida para a abordagem no trato da língua e da cultura indígena. O segundo livro, "Projeto Arariba", não fez nenhum progresso frente às orientações sugeridas pelo Ministério de Educação e Cultura, referente a uma apresentação positiva e atualizada, capaz de contribuir para os estudos étnicorraciais no contexto escolar

É evidente, em ambos os livros, a negação do índio enquanto sujeito da sua história, principalmente no segundo, pois a falta de reconhecimento desses grupos étnicos minoritários é ainda uma etapa a ser vencida. No entanto, o primeiro livro, "Diálogo", progride quando traz escritores indígenas com formação universitária, apresenta um índio contemporâneo que transita da aldeia à cidade sem deixar de ser índio. Mas, concernente às atividades, todavia, o livro ainda precisa repensar as suas propostas de atividades, visando uma prática reflexiva e atualizada no que se refere à situação dos povos indígenas do Brasil.

Deve-se considerar inovador o fato de o livro didático dedicar um capítulo exclusivo para tratar dos indígenas do Brasil, pois como vimos anteriormente, o índio mal aparecia nos manuais didáticos em específico na década de 1980. Porém, por mais que o manual traga um dado novo, ainda é perceptível a dedicação de poucas páginas para tratar da referida temática. Tudo é mencionado de forma muito rápida e irrisória. As próprias imagens que aparecem no livro retratam o indígena ligado somente à mata e à selva, caçando, vivendo em "harmonia com a natureza", o que reforça a imagem que tanto se buscou desconstruir, ao longo da história, ou seja, mostrar que o indígena não deixa de ser índio pelo fato de ser escolarizado e morar em outros locais, dentre eles, as cidades.

É nesse ponto de vista que identificamos a necessidade da participação do professor como mediador no processo de formação do conhecimento, pois sem a inserção do professor, o manual didático reforça preconceitos e deixa de ser uma ferramenta favorável à formação, tornando-se uma arma perigosa ao disseminar o preconceito e não desconstruir a ideia cristalizada de que o índio é obrigado a viver na mata e, quando sai dela, deixa de ser índio. Lamentavelmente, esses aspectos ainda são apresentados de maneira sucinta, quando não equivocada, em alguns livros didáticos de ensino de língua portuguesa, inegavelmente, essas leituras viriam possibilitar, entre outros proveitos, “[...] o desenvolvimento do professor e a reelaboração do seu saber eurocêntrico" (SILVA, 2001, p. 57), o que, certamente, os levaria a uma tomada de consciência crítico-reflexiva e ao resgate da cidadania dos povos indígenas.

Outro tema que deve ser aludido é quanto ao ocultamento da língua indígena. Esse aspecto linguístico, quando citado nos manuais didáticos, é bem superficial, sinalizando um léxico ou outro de origem indígena no campo culinário, religioso e geográfico. Sendo assim, os dois manuais didáticos estão distantes da proposta do MEC. É claro que o segundo livro se distanciou muito mais, e isso nos mostrou que não houve uma intervenção pedagógica plena em conformidade com as recomendações indicadas pelas Orientações do MEC.

Portanto, além destes posicionamentos, a retomada do orgulho de ser índio, a luta dos povos indígenas pela reafirmação e fortalecimento de suas identidades, como 
propõem as lideranças de suas organizações sociais, devem ser levadas em consideração no ensino e nos livros didáticos, para um tratamento mais adequado das culturas indígenas nas escolas não indígenas. Assim, Rajagopalan afirma a importância de se entender identidade como algo que está sempre em fluxo, em construção, investida de ideologia, ligada à ideia de interesses e, por natureza, fincada nos domínios sócio-políticos. Afinal, o sujeito discursivo é sócio-historicamente marcado e atravessado por conotações ideológicas, (RAJAGOPALAN, 2003, p. 32).

Mediante a análise dos livros didáticos realizada, foi possível constatar mudanças e permanências em relação à forma de tratar o indígena. Como já foi mostrado acima, muitos estereótipos persistem, porém, já existem algumas transformações positivas em relação ao tratamento aos povos indígenas. De fato, ainda são necessárias mudanças significativas na forma de tratar os diversos povos indígenas do Brasil nos manuais didáticos, a fim de se pensar a importância de trabalhar mais e melhor a presença do indígena no processo histórico, identitário e cultural, para que em algum momento da nossa história, alcancemos a tão almejada igualdade social.

Buscamos, neste trabalho, evidenciar o lugar que a cultura indígena ocupa nos Livros Didáticos de Língua Portuguesa, a produção do conhecimento referente aos estudos dos povos indígenas, assim como os desdobramentos éticos, políticos e culturais, voltados para o campo educacional em geral.

Com essa posição, o Livro Didático de Língua Portuguesa, mesmo após a publicação da Lei 11645/08, delineia sua discordância da imparcialidade advogada pelos órgãos responsáveis concernente à distribuição de tal material às escolas públicas do Brasil, perpetuando uma prática de interesses políticos cuja representação ainda favorece um olhar etnocentrado com relação às minorias étnicas.

Assim, a análise realizada nos livros didáticos de LP no $9^{\circ}$ ano do Ensino Fundamental já aponta caminhos para a discussão acerca das culturas indígenas, como prevêem Os Parâmetros Curriculares Nacionais no tocante ao tema transversal sobre Educação para as Relações Etnicorraciais, o que consideramos avanços. Mas, apresentam lacunas com relação à representação dos povos indígenas, ao contexto histórico de suas línguas e ao legado linguístico-cultural na formação do povo brasileiro, negando aspectos imprescindíveis para discussão no contexto escolar. Essa perspectiva torna-se importante para que o discurso tenha um sentido amplo, transdisciplinar e possa, assim, evidenciar a relação existente entre textos, gêneros e contextos sociais importantes no processo de formação de um aluno crítico, atualizado e informado acerca da sua própria história.

\section{REFERÊNCIAS}

ANCHIETA, José de. Cartas, informações, fragmentos históricos e sermões I Quadrimestre de Maio a Setembro de 1554. Rio de Janeiro: Civilização Brasileira, 1933. 
ANDRADE, Oswald. Erro de português. Disponível em: https://todahoratemhistoria.wordpress.com/2014/07/28/erro-de-portugues-deoswald-de-andrade/. Acesso em: 15 jan. 2018.

BELTRÃO, Eliana Santos; GORDILHO, Teresa. Lingua Portuguesa. Coleção Diálogo. $9^{\circ}$ Ano. São Paulo: Editora FTD, 2009

BEZERRA, M. A. Textos: seleção variada e atual. In: Angela Paiva Dionízio, Maria Auxiliadora Bezerra (orgs). O livro didático de Português: múltiplos olhares. 2 ed. Rio de Janeiro: Lucerna, 2003.

BRASIL. Conselho Nacional de Educação. Parecer CNE/CP 3/2004. Diretrizes Curriculares Nacionais para a Educação das Relações étnico-raciais para o ensino de história e cultura afro-brasileira e africana. Brasília, 2004.

. Ministério da Educação. Referencial Curricular Nacional para as Escolas Indígenas. Brasília: Secretária de Educação Fundamental/MEC, 1998.

Secretaria de Educação Fundamental. Parâmetros curriculares nacionais: terceiro e quarto ciclos do ensino fundamental: língua portuguesa. Brasília: MEC/SEF, 1998.

. Sistema Educativo Nacional do Brasil. Capitulo 9: Educação Escolar Indígena). Brasília: Ministério da Educação do Brasil (MEC/INEP) y Organización de Estados Iberoamericanos, 2002.

CAMINHA, Pero Vaz. A Carta. In CASTRO, Silvio. A carta de Pero Vaz de Caminha. Porto Alegre: L\&PM, 1996.

CANCLINI, Nestor Garcia. Culturas Híbridas: estratégias para entrar e sair da modernidade. 4. ed. São Paulo: UNESP, 2011.

CHARTIER, Roger. A História Cultural: entre Práticas e Representações. Tradução de Maria Manuela Galharda. 2.ed. Difel-Difusão, 2002.

CUNHA, Manuela Carneiro da. (org.). História de Índios no Brasil. São Paulo: Companhia das Letras: Secretaria Municipal de Cultura: FAPESB, 1992.

CUNHA, Rejane Cristine Santana. O Fogo de 51: reminiscências Pataxó. Dissertação de mestrado apresentado à UNEB, Santo Antônio de Jesus, 2010.

D’Angelis, Wilmar R. Como nasce e por onde se desenvolve uma tradição escrita em sociedades de tradição oral. São Paulo: Campinas: Editora Curt Nimuendajú, 2007. 
FREITAG, Barbara; MOTTA, Rodrigues Valeria; COSTA, Wanderly Ferreira. O estado da arte do livro didático no Brasil. Brasília, INEP/REDUC, 1987.

FUNARI, Pedro Paulo; PINÓN, Ana. A Temática Indígena na Escola: subsídios para os professores. São Paulo: Contexto, 2011.

HALL, Stuart. A identidade cultural na pós-modernidade. 11.ed. Rio de Janeiro: DP\&A, 2006.

. Quem precisa da identidade? IN: SILVA, Tadeu Tomaz da (Org). In: Identidade e diferença: a perspectiva dos Estudos Culturais. Petrópolis, RJ: Vozes, 2011.

KLEIMAN, Angela B. Agenda de pesquisa e ação em Linguística Aplicada: problematizações. In: MOITA LOPES, L. P. DA (org.) Linguistica Aplicada na Modernidade Recente. $1^{\mathrm{a}}$ ed. - São Paulo: Parábola, 2013.

LACERDA, Rosane. Os Povos Indígenas e a Constituinte (1987-1988). Brasília: Conselho Indigenista Missionário, 2008.

- Diferença não é incapacidade: gênese e trajetória histórica da concepção da incapacidade indígena e sua insustentabilidade nos marcos do protagonismo dos povos indígenas e do texto constitucional de 1988. 2007. 2 v. Dissertação (Mestrado em Direito)Universidade de Brasília, Brasília, 2007.

MOITA LOPES, Luiz Paulo. Socioconstrucionismo: discurso e identidade social. In: MOITA LOPES, Luiz Paulo (Org.). Discursos de identidades: discurso como espaço de construção de gênero, sexualidade, raça, idade e profissão na escola e na família. Campinas, SP: Mercado das Letras, 2003.

MOISÉS-PERRONE, Beatriz. Índios livres e índios escravos: os princípios da legislação indigenista do período colonial (século XVI a XVIII). In: CUNHA, Manuela Carneiro da.(org.). História de Índios no Brasil. São Paulo: Companhia das Letras: Secretaria Municipal de Cultura: FAPESB, 1992.

Programa Nacional do Livro Didático (PNLD). In: ROJO, R.; BATISTA, A. (Orgs.) Livro Didático de Língua Portuguesa: Letramento e Cultura da Escrita. Campinas, SP: Mercado de Letras, 2003.

PROJETO ARARIBÁ: Lingua Portuguesa. 9 ano: Ensino Fundamental. 3. ed. São Paulo: Moderna, 2010. 
RAJAGOPALAN, Kanavillil. Por uma linguística crítica. In: Por uma linguística crítica: linguagem, identidade e a questão ética. São Paulo: Parábola, 2003.

- O conceito de identidade em linguística: é chegada a hora para uma reconsideração radical? In: SIGNORINI, I. (Org). Lingua(gem) e identidade: elementos para uma discussão no campo aplicado. Campinas: Mercado de Letras, 1998.

RIBEIRO, Darcy. Os Índios e a Civilização: a integração das populações indígenas no Brasil Moderno. Rio de Janeiro: Editora Civilização Brasileira, 1970.

RODRIGUES, Aryon Dall'igna. Linguas brasileiras: para o conhecimento das línguas indígenas. São Paulo: Edições Loyola, 2002.

SANTOMÉ, Jurjo Torres. As culturas negadas e silenciadas no currículo. In: SILVA, Tomaz Tadeu (org.). Alienígenas na sala de aula: uma introdução aos estudos culturais em educação. Petrópolis, 1995.

SILVA, Ana Célia da. Desconstruindo a discriminação do negro no livro didático: o que mudou? por que mudou? Salvador: EDUFBA, 2011.

SILVA, Tadeu Tomaz da (Org). Identidade e diferença: a perspectiva dos Estudos Culturais. Petrópolis, RJ: Vozes, 2011.

VAINFAS, Ronaldo. Trópico dos pecados, moral, sexualidade e inquisição no Brasil. Rio de Janeiro. Campus, 1989.

WOODWARD, Kathryn. Identidade e diferença: uma introdução teórica e conceitual. In: SILVA Tomaz Tadeu (Org.). Identidade e diferença: a perspectiva dos estudos culturais. 6. Ed. Petrópolis: Vozes, 2006.

Recebido em: 15/07/2017

Aprovado em: 22/10/2017

Publicado em: 30/12/2017 